\title{
La follia di Tristano. Redazione del manoscritto di Berna, a cura di C. CONCINA
}

\section{Maria Colombo Timelli}

\section{(2) OpenEdition}

\section{Journals}

\section{Édition électronique}

URL : https://journals.openedition.org/studifrancesi/44605

DOI : 10.4000/studifrancesi.44605

ISSN : 2427-5856

Éditeur

Rosenberg \& Sellier

\section{Édition imprimée}

Date de publication : 1 août 2021

Pagination : $344-345$

ISSN : 0039-2944

\section{Référence électronique}

Maria Colombo Timelli, «La follia di Tristano. Redazione del manoscritto di Berna, a cura di C. concina », Studi Francesi [En ligne], 194 (LXV | II) | 2021, mis en ligne le 06 septembre 2021, consulté le 14 octobre 2022. URL : http://journals.openedition.org/studifrancesi/44605 ; DOI : https://doi.org/ 10.4000/studifrancesi.44605

Ce document a été généré automatiquement le 14 octobre 2022

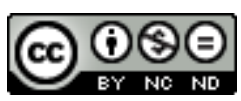

Creative Commons - Attribution - Pas d'Utilisation Commerciale - Pas de Modification 4.0 International - CC BY-NC-ND 4.0

https://creativecommons.org/licenses/by-nc-nd/4.0/ 


\title{
La follia di Tristano. Redazione del manoscritto di Berna, a cura di C. CONCINA
}

\author{
Maria Colombo Timelli
}

\section{RÉFÉRENCE}

La follia di Tristano. Redazione del manoscritto di Berna, a cura di C. ConcinA, Roma, Carocci, 2019, «Biblioteca Medievale» 156, 112 pp.

1 Les éditions de la Folie de Berne ne manquaient certes pas, ni les traductions en français, ni encore les traduction en italien (Alberto Del Monte 1952, Angela Bianchini 1957, plus récemment Walter Pagani 2015): Chiara Concina en donne la liste complète en ouverture de sa bibliographie (pp. 99-199). Ce qui justifie cette nouvelle édition d'un texte transmis par un manuscrit unique et un fragment, ce n'est donc ni l'intérêt philologique, ni l'intérêt littéraire - malgré la beauté d'un texte qui dans un peu moins de 600 octosyllabes réussit l'exploit d'évoquer tout entière l'histoire d'un amour légendaire -, mais essentiellement le débat critique que ce récit a suscité: «Il testo che qui si propone, ricontrollato direttamente sul codice $B$, non vuole essere tanto una nuova edizione, quanto una rilettura critica che si avvale costantemente dei contributi e delle edizioni precedenti» (Nota al testo, p. 35, c'est moi qui souligne).

2 Articulée en trois volets, l'Introduction fait le point sur les questions fondamentales: la discussion sur la place des deux Folies, de Berne et d'Oxford, au sein du corpus tristanien, et sur leur relation réciproque (on verra la contribution fondamentale de Cesare Segre dans "Medioevo Romanzo" 25, 2001); puis la comparaison entre les deux versions, à la fois très proches pour le sujet et distantes quant au style de chacune; enfin, l'organisation de la matière dans la Folie de Berne, et surtout sa péculiarité, qui consiste à mêler - selon les mots de Mario Mancini cités ici p. 31 - «le forme della cortesia con elementi arcaici e selvaggi...». 
3 L'édition est fondée sur le manuscrit de Berne (Bürgerbibliothek, 534; fin XIII -début $\mathrm{XIV}^{\mathrm{e}}$ siècle, d'origine bourguignonne), alors que le manuscrit de Cambridge (Fitzwilliam Museum, 302; XIII siècle, copié en Angleterre) est édité en annexe: ce choix nous paraît judicieux, dans la mesure où ce fragment d'une soixantaine de vers en comprend néanmoins douze de plus que le passage correspondant dans Berne. Les deux textes sont accompagnés d'apparat en pied de page et de notes finales, consacrées à des remarques linguistiques (lexique, locutions, morphologie) et littéraires (nombreux renvois aux autres textes de la tradition tristanienne), sans négliger les difficultés d'interprétation de certains vers (avec une attention bienvenue pour la ponctuation). La traduction essaie de reproduire en italien, par l'adoption des «novenari ad accento libero» (p. 17), le rythme coulant de l'octosyllabe médiéval; on saluera cet effort, même si C.C. en est amenée à s'éloigner parfois du texte original. Un seul exemple, au tout début du texte: «Mout est Tritanz mellez a cort, Ne set o aille në ou tort» (v. 1-2) / «Tristano a corte è compromesso, non sa dove andare o fuggire», avec perte de l'antonymie totalisante aller / torner. Je me permets aussi de signaler le seul endroit où l'édition me paraît douteuse: Dinas a informé Tristan «Con a perdu par nonsavoir L'amor del roi, quil [h]et de mort» (vv. 38-39, pas de commentaire dans les notes); la syntaxe et le sens de la phrase imposeraient de transcrire, me semble-t-il, «L'amor del roi, qui l'[h]et de mort».

5 La bibliographie (pp. 99-109) comprend, comme on l'a dit, la liste des éditions et des traductions italiennes, les sources primaires et les études critiques. 